Full length article

\title{
Separate and combined effects of neurotoxic and lytic compounds of Alexandrium strains on Mytilus edulis feeding activity and hemocyte function
}

\author{
Virginia Angélica Bianchi ${ }^{\mathrm{a}, *}$, Hendrick Langeloh ${ }^{\mathrm{b}}$, Urban Tillmann ${ }^{\mathrm{b}}$, Bernd Krock ${ }^{\mathrm{b}}$, \\ Annegret Müller ${ }^{\mathrm{b}}$, Ulf Bickmeyer ${ }^{\mathrm{b}}$, Doris Abele ${ }^{\mathrm{b}}$ \\ ${ }^{a}$ Laboratorio de Ecotoxicología Acuática, INIBIOMA (CONICET-UNCo) - CEAN, ruta provincial No 61, km 3, CCP 7, Junín de los Andes, 8371, Neuquén, Argentina \\ ${ }^{\mathrm{b}}$ Alfred Wegener Institute for Polar and Maine Research, Am Handelshafen 12, 27570, Bremerhaven, Germany
}

\section{A R T I C L E I N F O}

\section{Keywords:}

Blue mussel

Paralytic shellfish toxins

Lytic activity

Filtering activity

Immune response

\begin{abstract}
A B S T R A C T
Multiple toxic and bioactive compounds produced by Alexandrium spp. cause adverse effects on bivalves, but these effects are frequently difficult to attribute to a single compound class. To disentangle the effect of neurotoxic vs lytic secondary metabolites, we exposed blue mussels to either a paralytic shellfish toxin (PST) producing Alexandrium spp. strain, or to an exclusively lytic compound (LC) producing strain, or a strain containing both compound classes, to evaluate the time dependent effects after 3 and 7 days of feeding. Tested parameters comprised signs of paralysis, feeding activity, and immune cell integrity (hemocyte numbers and viability; lysosomal membrane destabilization) and function (ROS production). Both compound classes caused paralysis and immune impairment. The only effect attributable exclusively to PST was increased phagocytic activity after 3 days and impaired feeding activity after 7 days, which curtailed toxin accumulation in digestive glands. Lysosomal membrane destabilization were more closely, but not exclusively, matched with LC exposure. Effects on circulating hemocyte integrity and immune related functions were mostly transient or remained stable within 7 days; except for increased lysosomal labialization and decreased extracellular ROS production when mussels were exposed to the toxin combination. M. edulis displays adaptive fitness traits to survive and maintain immune capacity upon prolonged exposure to environmentally relevant concentrations of PST and/or LC producing Alexandrium strains.
\end{abstract}

\section{Introduction}

Species of the dinoflagellate genus Alexandrium are the major sources of paralytic shellfish toxins (PST) among microalgae species and form harmful algae blooms (HABs) in coastal and shelf seas [1]. The species-specific portfolio of PST encompasses the highly toxic derivative saxitoxin (STX), as well as neosaxitoxin (NEO), gonyautoxins (GTX1-GTX4), and a sub-group of C1-4 PST called $N$-sulfocarbamoyl toxins [2]. Although all of these compounds are water-soluble, they are not readily released into the dissolved phase by intact cells [3]. Instead, the PST accumulate throughout the food chain of algal grazers and filter feeders [4,5] to values of above $80 \mu \mathrm{g}$ saxitoxin equivalents $100 \mathrm{~g}^{-1}$, the regulatory limit for meat consumption. These toxic compounds produce severe neurological and even potentially fatal symptoms in humans, based on reversible blocking of the voltage-gated $\mathrm{Na}^{2+}$ channels (paralytic shellfish poisoning) [6].

Bivalve mollusks filter cells from the water at different rates, digest the toxic algae [7-10], and accumulate and partly metabolize ingested toxins [11]. Bivalve resistance to the toxic effects of PST varies between species according to the differences in the saxitoxin-binding site of the sodium channel [12]. The spectrum of functional responses of bivalves to Alexandrium strains encompasses disturbance of feeding activity and movement [13,14], larval development [15], tissue integrity, gamete viability [16] and survival [17]. Recently, the role of the hemocyte cells, the main effectors the bivalve innate immune system $[18,19]$, in the sub-lethal effects of PST on bivalves have come into focus. Studies into the immunosuppressive and immunostimulating effects of these toxins in clams [3,14,20], oysters [4,21,22] and mussels [23] have applied environmentally relevant $\mathrm{HAB}$ cell concentrations. It resulted that the immunotoxicity of neurotoxins depends on fitness of the affected bivalves, the duration of exposure, and the individual history of previous toxin exposure.

Studying effects of PST on bivalves using Alexandrium spp. cultures is, however, complicated, by the fact that species of Alexandrium - in addition to PST-produce other poorly characterized bioactive compounds with lytic and cytotoxic activity [24]. Bioactive compounds

\footnotetext{
* Corresponding author.

E-mail address: vabianchi@comahue-conicet.gob.ar (V.A. Bianchi).
} 

Abbreviations:
PST Paralytic shellfish toxins
BC Bioactive compounds
LC Lytic compounds
ROS Reactive oxygen species

(BC) are foud in cell-free culture supernatants [3,25] and associated to cytosol [26] and to cytosol-free cell fragments [17]. One of the known effects of bioactive compounds is allelopathy, which favors the development of certain algae species over others by inhibiting competitor growth, reproduction and survival [27-29]. Bioactive compounds affect bivalves and fish, causing alterations of growth and behavior, tissue damage and molecular dysfunction resulting in massive mortality events [30]. Particularly, compounds with lytic activity (LC) are produced by most strains of Alexandrium and are chemically unrelated to the known PST [24].

The presence of multiple toxins in Alexandrium spp. makes it difficult to unequivocally attribute adverse effects on bivalves to a single compounds class, especially when experimental strains are not fully characterized with respect to their portfolio of different compounds. In spite of increasing awareness of their frequent co-occurrence during harmful algal bloom events, combined effects of PST and BC on bivalves are insufficiently understood. The potential of producing BC is not always assessed in Alexandrium strains used for testing PST effects on bivalves [4,15]. Moreover, some previous studies, e.g. Refs. [15,17], did not provide sequence information for their specific experimental strains. It is now generally accepted that sequence data are required for a reliable species designation of the former Alexandrium tamarense/ fundyense/catenella species complex [31], which in turn is needed for a comparison of data and effects at the Alexandrium species level. First experimental studies in which different bivalves and their early life stages were exposed simultaneously to both toxin types yielded contradictory results $[13,29]$. In this study, we followed a comparative approach with PST and/or LC producing strains of Alexandrium spp., to evaluate the time dependent effects of exposure in blue mussels, Mytilus edulis, and to investigate their effects on the feeding activity (avoidance behavior) and immune cell integrity and function. We exposed mussels separately to microalgae producing PST or LC and tested combined effects of toxins using a PST and LC producer microalgae.

\section{Materials and methods}

\subsection{Algal strains}

Different Alexandrium strains, previously characterized by morphology and phylogenetic sequence, were chosen based on their known capability to produce PST and LC. Two clones of A. catenella (formerly group I of the A. tamarense/fundyense/catenella species complex) were shown to produce PST, whereas Alex2 but not Alex5 also displayed lytic activity (Alex5 (PST); Alex2 (PST + LC)). Both Alexandrium strains were isolated from the North Sea coast off Scotland [32]. In addition, a strain of Alexandrium tamarense (AlexNX-57-08, formerly group III of the A. tamarense/fundyense/catenella species complex) isolated in 2015 from the Trondheimfjord (Norway) (Tillmann, unpublished), was applied as a lytic strain that does not produce PST.

All strains were grown in a seawater K-medium supplemented with selenite, prepared from $0.2 \mathrm{~mm}$ sterile-filtered (VacuCap, Pall Life Sciences, Dreieich, Germany) North Sea seawater (salinity $32 \mathrm{ps} \mu$ ) at $15{ }^{\circ} \mathrm{C}$, under cool-white fluorescent light at a photon flux density (PFD) of $100 \mu \mathrm{mol}$ photons $\mathrm{m}^{-2} \mathrm{~s}^{-1}$ on a $16 \mathrm{~h}$ light: $8 \mathrm{~h}$ dark photo-cycle. Cultures were harvested in early stationary phase for feeding experiments.

Nannochloropsis salina (NYOS ${ }^{\circledR}$ PhytoMaxx, $\mathrm{N}^{\circ}$ 12009) was used as non-toxic food in control treatments. $N$. salina is a small $(2-5 \mu \mathrm{m}$ diameter) non-motile single cell algae, recommended for feeding of filter feeding organisms. Feeding potential of Mytilus sp. upon Nannochloropsis sp. was taken from Okumus et al. [33].

\subsection{Toxin measurements}

Cell density was evaluated in all algal cultures at the beginning of each experiment by direct counting, using a sedimentation chamber for Alexandrium (by triplicate, under inverted microscope Axiovert 25) and a Fuchs Rosenthal chamber for $N$. salina (by quadruplicate, under light microscope). Cell pellets ( $15 \mathrm{~min}$ at $3200 \times \mathrm{g}$, for Alexandrium; $30 \mathrm{~min}$ at $10000 \times g$, for control strain) from known culture volumes were used for PST extraction in $0.03 \mathrm{~N}$ acetic acid. Toxin profiles and content were analyzed by reverse-phase ion-pair liquid chromatography coupled to post-column derivatization and fluorescence detection (LC-FD) based on previously published methods [11,34]. Data were calibrated against external PST calibration curves prepared from standards purchased from the Certified Reference Material Programme of the Institute of Marine Biosciences, National Research Council, Halifax, NS, Canada. Results are expressed as pg per cell. The presence of extracellular bioactive compounds with lytic capacity was quantified using a whole cell cryptophyte Rhodomonas salina (strain KAC30) bioassay [32,35]. $\mathrm{EC}_{50}$ was calculated from the sigmoidal curve fit of non-linear regression applied to the log-transformed $A$. catenella cells concentrations vs. $\%$ of $R$. salina intact cells. Results are expressed as $\mathrm{EC}_{50}$ cells per $\mathrm{mL}$, including 95\% confidence intervals (CI).

\subsection{Mussel collection and maintenance}

Experiments were carried out in August-September 2016. Adult $M$. edulis ( $45.8 \pm 2.9 \mathrm{~mm}$ of shell length, commercial size) were collected at the island of Sylt and transported to the Alfred Wegener Institute in Bremerhaven. According to official controls, these areas are not affected by toxic blooms. Mechanically cleaned mussels were acclimatized for 21 days in tanks with circulating seawater $\left(32.8 \mathrm{ps} \mu, 8.13 \pm 0.5^{\circ} \mathrm{C}\right.$, $0.15 \mathrm{mg} \mathrm{L}^{-1} \mathrm{NH}_{4}{ }^{+}, 0.02 \mathrm{mg} \mathrm{L}^{-1} \mathrm{NO}_{2}{ }^{-}, 26.53 \mathrm{mg} \mathrm{L}^{-1} \mathrm{NO}_{3}{ }^{-}, \mathrm{pH} 8.02$, $10.68 \mathrm{mg} \mathrm{L}^{-1}$ dissolved oxygen). Mussels were fed every 7 days with $N$. salina cells (manufacturer's recommended amount). Feeding was stopped 7 days before starting the experiments to intensify filtration activity of mussels.

\subsection{Experimental design}

After acclimatization, mussels were sorted into four groups and treated as 6 replicate subgroups for each treatment. These replicates consisted in groups of five individuals placed in plastic containers, separated from the bottom by a rigid plastic mesh. Water mixing was achieved through mild air bubbling, which also maintained the algae in suspension as described by Bianchi et al. [36]. Four dietary treatments were applied: 1) Control: N. salina cells; 2) PST: Alex5 cells (producer of PST but not LC); 3) LC: AlexNX-57-08 cells (producer of LC but not PST) and 4) PST + LC: Alex2 cells (producer of PST and LC). Triplicate control experiments without mussels were conducted to assess changes in cell concentrations. Treatment groups will be referred to as control, Alex5 (PST), AlexNX-57-08 (LC) and Alex2 (PST + LC), for convenience.

Cell concentrations and exposure duration were chosen based on environmentally realistic conditions registered for HABs of Alexandrium and their effects on bivalves $[5,15]$. Considering that $N$. salina cells are about 30 times smaller than $A$. catenella cells, the control diet was set at 154,000 cells $\mathrm{mL}^{-1}$ and toxic diets were set at 500 cell mL${ }^{-1}$ in order to offer equal biomass according to volume. Each container was filled to a final volume of $500 \mathrm{~mL}$ by mixing the original algae culture with filtered seawater $(0.2 \mu \mathrm{m}$ pore filter) to reach the indicated cell concentration. Valve opening (indicating filtration) of every mussel was 
checked after $30 \mathrm{~min}$ of adding cells to the containers. Diets were offered daily in two separated experiments for periods of 3 and 7 days; water was exchanged every day before feeding (water temperature $\left.8.2 \pm 0.3^{\circ} \mathrm{C}\right) . M$. edulis acclimated to laboratory conditions at water temperature slightly above $8{ }^{\circ} \mathrm{C}$ maintains a relatively constant feeding rate [37,38] and metabolic activity [39]. Alexandrium catenella and $A$. tamarense occur and can bloom in temperate and cold coastal areas (e.g. Ref. [40]), so the temperature difference between growth and experimental conditions should not be a problem. The presence of some Alexandrium temporary cysts in our experiment has also been reported in other studies carried out at $16^{\circ} \mathrm{C}$ [5]; thus, it is frequently occurring in bivalve feeding treatments and not related to the shift of temperature between algae culture and mussel exposure conditions. After both experimental periods, mussels were checked for their general condition indices, hemolymph was sampled for hematological analysis and digestive glands were excised for PST accumulation measurements.

\subsection{General condition indices}

\subsubsection{Feeding activity}

During the feeding periods and before every exchange of water, two aliquots $(50 \mathrm{~mL})$ of water with fecal pellets were taken from each container and fixated with Lugol $0.05 \%$. Algal cells were counted as described before (section 2.2), and the presence/absence of cells attached to feces/pseudo-feces pellets (and thus not digested by the bivalves) was recorded for each control and Alexandrium treated container [5]. Results are expressed as percentage of cells consumed per day and container $(n=6)$.

\subsubsection{Paralysis test}

Paralysis was assessed at the end of each period (3d, 7d) by checking the mantle retraction response in every mussel from each container (5 mussels per container, $\mathrm{n}=30$ ). Mussels showing no mantle retraction after mechanical stimulation were considered paralyzed [13]. Mortality was recorded on a daily basis.

\subsubsection{Condition index}

After 3- and 7-days of exposure, one mussel from each container was opened by adductor muscle incision $(n=6)$. Soft tissue and valves were removed, dried for $48 \mathrm{~h}$ at $60^{\circ} \mathrm{C}$, and weight recorded of each organ. Condition index (CI) is expressed as dry soft tissue mass (g)/total shell length $(\mathrm{cm})$ ratio.

\subsubsection{PST accumulation in digestive gland}

After 3 and 7 days of exposure, two mussels per experimental container were opened by adductor muscle incision $(n=6)$. Digestive glands were excised, weighed, and frozen at $-20^{\circ} \mathrm{C}$ (the 2 digestive glands per container were pooled into one vial). Later on, pooled samples were homogenized (Ultra Turrax T25, IKA Werke, Staufen, Germany) and PST were extracted using $0.2 \mathrm{M} \mathrm{HCl}$ and following the protocol of Luckas et al. [41]. Toxin profiles and analyzed components were quantified as described above (section 2.2). Results are expressed as total PST content $(\mu \mathrm{g})$ per wet weight $(\mathrm{g})$ of tissue.

\subsection{Hemocyte analyses}

Hemolymph was drawn from the posterior adductor muscle of each mussel using a sterile syringe and aliquoted in microcentrifuge tubes for immediate analysis. One mussel per container was used for lysosome stability and phagocytosis measurements, and the last mussel for hemocyte countings and ROS production measurements $(n=6$, for each analysis). Bivalves and samples were constantly kept on ice. The syringe was prefilled with sterile Alseve medium $\left(20.8 \mathrm{~g} \mathrm{~L}^{-1}\right.$ glucose; $8 \mathrm{~g} \mathrm{~L}^{-1}$ sodium citrate; $3.36 \mathrm{~g} \mathrm{~L}^{-1}$ EDTA; $22.5 \mathrm{~g} \mathrm{~L}^{-1} \mathrm{NaCl}$; pH 7; $920 \mathrm{mOsm}$; Novas et al. [42]), used as anticoagulant and nutritive medium for the cells (1:5, medium:hemolymph), except for phagocytic activity assays.

\subsubsection{Cytotoxicity}

Lysosomal membrane stability $(n=6)$ was assessed using the Neutral Red Retention (NRR) assay adapted for microplate reading (modified from Coles et al. [43]). Duplicate samples of $300 \mu \mathrm{L}$ hemolymph per animal were placed into round-bottom dark brown microcentrifuge tubes and kept open and cold (over ice) during the assay. Briefly, $150 \mu \mathrm{L}$ of $200 \mu \mathrm{M}$ neutral red solution (NR obtained from $100 \mathrm{mM}$ stock solution in DMSO) were added, and the suspension was gently mixed and incubated for $1 \mathrm{~h}$, over ice. Sample controls were conducted in tubes with DMSO void of NR. After incubation, samples were centrifuged $\left(800 \times g\right.$ for $5 \mathrm{~min}$ at $\left.10^{\circ} \mathrm{C}\right)$ and cells were washed once with $1 \mathrm{~mL}$ of Alseve medium. Extraction buffer (1\% acetic acid and $50 \%$ ethanol in distilled water) was added to the resulting pellet and incubated in closed tubes for $1 \mathrm{~h}$, at room temperature. Samples were centrifuged again, and $150 \mu \mathrm{L}$ aliquots of supernatant were pipetted into a 96 well plate. Absorbance was read at $550 \mathrm{~nm}$. Baseline readings were conducted using extraction buffer controls. Results are expressed as optical density (OD) per $\mu \mathrm{g}$ of protein (Bradford [44]), with lower absorbance indicating stronger labilization of lysosomal membranes.

Hemocytes viability $(n=6)$ was measured using the trypan blue staining method (modified from Akaishi et al. [45]). $100 \mu \mathrm{L}$ of hemolymph were centrifuged $\left(500 \times g\right.$ for $20 \mathrm{~min}$ at $\left.4{ }^{\circ} \mathrm{C}\right)$ to eliminate the humoral compartment and, cells were re-suspended in the same volume of Alseve medium. Cell suspension was mixed with $50 \mu \mathrm{L}$ of trypan blue stain $0.2 \%$ (Fluka) and incubated at $4{ }^{\circ} \mathrm{C}$ for $5 \mathrm{~min}$. Live (unstained) and dead cells (stained) were counted within $15 \mathrm{~min}$, using a Fuchs Rosenthal chamber and a light microscope. The number of viable hemocytes per $\mathrm{mL}$ is expressed as percentage of total cells.

\subsubsection{Total circulating hemocyte count and phagocytic activity}

Total number of cells in hemolymph $(n=6)$ was determined microscopically in quadruplicate using a Fuchs Rosenthal chamber. Results are expressed as number of cells $\mathrm{mL}^{-1}$. Phagocytic activity $(\mathrm{n}=6)$ was assessed using yeast cells stained with Congo red (Sigma). $100 \mu \mathrm{L}$ of hemolymph were mixed with stained yeast suspension containing twice the amount of yeast cells than the amount of viable hemocytes in hemolymph. This mix was incubated for $30 \mathrm{~min}$ on ice. After the incubation, cells were fixated with glutaraldehyde $1 \%$ and kept at $4{ }^{\circ} \mathrm{C}$. 300 hemocytes per mussel were analyzed under the light microscope and, phagocyted yeast cells counted. Results are expressed as number of phagocyted yeast cells/number of hemocytes analyzed (modified from Kuchel et al. [46]).

\subsubsection{ROS production}

For ROS production measurements, hemolymph $(\mathrm{n}=6)$ was centrifuged for $20 \mathrm{~min}$ at $500 \times \mathrm{g}$ and $4{ }^{\circ} \mathrm{C}$. The supernatant was removed and cells were re-suspended in Alseve medium and kept on ice for $30 \mathrm{~min}$ before analysis. Cell number and viability were determined in the suspension as described in section 2.6.1 and 2.6.2.

Intracellular ROS production was measured using dichlorofluorescein-diacetate $\left(\mathrm{H}_{2}\right.$ DCF-DA, Invitrogen) as fluorescent probe (based on Moss and Allam [47]). Triplicate aliquots containing 30000 viable cells were placed in each well, of a 96 well plate, with Alseve medium containing $40 \mu \mathrm{M} \mathrm{H}_{2}$ DCF-DA, in a final volume of $200 \mu \mathrm{L}$. The reaction mixture was incubated for $1 \mathrm{~h}$ in the dark at room temperature. Changes in fluorescence units were red for $1 \mathrm{~h}$ at $485_{\mathrm{ex}} / 530_{\mathrm{em}} \mathrm{nm}$, using a TRISTAR microplate reader (Fa. Berthold, Bad Wildbad, Germany). The background change of the fluorescence signal was measured after replacing cell suspension with Alseve medium, and autofluorescence in the samples was measured using DMSO without $\mathrm{H}_{2}$ DCF-DA. Results are expressed as fluorescent units (FU) per $10^{6}$ viable cells.

Extracellular ROS levels were measured using Amplex UltraRed reagent (life technologies), as fluorescent probe and horseradish peroxidase (GE Healthcare) as $\mathrm{OH}^{-}$generator, according to manufacturer's protocol. Triplicate aliquots containing 30000 viable cells were pipetted into each well, of a 96 well plate, and mixed with Alseve 
medium, containing $50 \mu \mathrm{M}$ of fluorescent probe and $0.2 \mathrm{U} \mathrm{mL}^{-1}$ of enzyme in a final volume of $200 \mu \mathrm{L}$. The reaction mixture was incubated for $5 \mathrm{~min}$ in the dark and changes in fluorescence units were followed for $1 \mathrm{~h}$ at $550_{\mathrm{ex}} / 590 \mathrm{em} \mathrm{nm}$, using a TRISTAR microplate reader (Fa. Berthold, Germany). Background changes in fluorescence were measured in wells where cell suspension was replaced by Alseve medium, and autofluorescence in each sample was measured adding DMSO without Amplex ${ }^{\circ}$ UltraRed. Results are expressed as FU per $10^{6}$ viable cells.

\subsection{Statistical analysis}

Data were expressed as mean \pm standard error of the mean (SEM). Normal distribution and homogeneity of variance were checked by Kolmogorov-Smirnov and Levene's tests, respectively. Data were transformed to arcsine of the square root when values were expressed as proportions. Differences among treatments for filtering activity and toxin accumulation in digestive gland were assessed using two way ANOVA with factors diet and time) and Newman-Keuls posthoc comparisons. For the rest of the variables, differences between treatments were determined using one way ANOVA and Newman-Keuls posthoc comparisons. Differences were considered significant at $p>0.05$.

\section{Results}

\subsection{Algal toxins}

\subsubsection{PST}

PST amounts were about 4.5 times higher in Alex 5 cells (PST) than Alex2 cells (PST + LC) (Table 1). Both strains used in feeding experiments contained detectable amounts of STX, NEO, GTX1/4, GTX2/3 and $\mathrm{C} 1 / \mathrm{C} 2$, at similar percentages, except for GTX2/3 in Alex 5 (PST) and GTX1/4 in Alex2 (PST + LC). There were no detectable PST amounts in N. salina (control) or in AlexNX-57-08 (LC) cells.

\subsubsection{Lytic compounds}

Cryptophyte $R$. salina bioassays showed that Alex2 (PST + LC) cultures used for the 3 days feeding experiment, displayed around 3 times more lytic activity than AlexNX-57-08 (LC) (EC 5094 cells per mL, CI 92 to 97, vs. $\mathrm{EC}_{50} 313$ cells per mL, CI 293 to 334); while for the 7 days experiment, lytic activity was around two times higher for the Alex2 (PST + LC) than for the AlexNX-57-08 culture (LC) $\left(\mathrm{EC}_{50}\right.$ 233 cells per mL, CI 222 to 246 , vs. EC 50556 cells per mL, CI 518 to 597). Alex5 (PST) culture supernatant had no detectable lytic activity (Fig. 1A and B) comparable to the $N$. salina control (data not shown).

\subsection{General mussel conditions}

Two-way ANOVA was significant for diet and time interaction $(p<0.001)$. M. edulis filtered between 95 and $98.5 \%$ of the total Alexandrium cells provided daily during the 3 day experiment, and no significant differences were observed when compared to the control (Table $2 \mathrm{~A}$ ). During the 7 day experiment, feeding activity was about $20-30 \%$ lower in mussels of the Alex5 (PST) treatment than in the rest of the treatments, showing significant differences at $5(p<0.001), 6$ $(p<0.01)$ and 7 days $(p<0.01)$ (Table 2 B). The observation frequency of algal cells attached to fecal pellets was less than $2 \%$ for all Alexandrium and control treatment containers.

After 3 days of feeding, 3\% of mussels from the Alex5 (PST) treatment were paralyzed (no mantle retraction); while $3 \%$ and $6 \%$ of mussels from AlexNX-56-08 (LC) the treatment were paralyzed after 3 and 7 days, respectively. Alex 2 (PST + LC) diet caused paralysis in 6\% and $12 \%$ of the mussels after 3 and 7 days, respectively. The condition index was not affected by diet on day 3 nor on day 7 (Table 2 A, B). Mortality of 3\% was registered in mussels of the Alex5 (PST) treatment after 7 days of feeding. No paralysis signals or mortalities were observed in control treatments.

\subsection{PST accumulation in digestive gland}

No PST were detected in digestive glands from control and AlexNX56-08 (LC) treatments. Two-way ANOVA was significant for diet and time interaction $(p<0.001)$ in mussels from Alex5 (PST) and Alex2 (PST + LC). After 3 days, the total amount of PST in digestive gland $(\mu \mathrm{g} / \mathrm{g})$ was 15 fold higher in mussels from Alex5 (PST) than in those from Alex2 (PST + LC) treatment $(p<0.001)$. After 7 days, toxin amount decreased to the half in Alex5 (PST)-treated groups ( $p<0.05$ ) and increased 3-fold in Alex2 (PST + LC) $(p<0.05)$, compared with 3 -day values. No significant differences were observed between treatments after 7 days of exposure. Results are shown in Fig. 2.

\subsection{Cytotoxicity}

After 3 days, lysosomal membrane stability was $40 \%$ lower in hemocytes of mussels of the Alex5 (PST), AlexNX-56-08 (LC) and Alex2 $(\mathrm{PST}+\mathrm{LC})$ treatments, than in those of the control $(p<0.05$, for all comparisons) (Fig. 3A). After 7 days, the effect of Alex5 (PST) and AlexNX-56-08 (LC) treatments was unchanged ( $p<0.05$, compared to the control) but a stronger effect was observed in the Alex2 (PST + LC) treatment, which resulted in $60 \%$ less membrane stability $(p<0.001)$, in comparison to the control (Fig. 3B).

Percentage of viable hemocytes in control treatments were $96 \%$ after 3 days and $90 \%$ after 7 days. For graphical clarity, the results obtained for Alexandrium treated groups were expressed as percentage of the control values (100\%). After 3 and 7 days, hemocyte viability reached a maximum of $20 \%$ lower values in mussels from Alex5 (PST) ( $\mathrm{p}<0.05 ; \mathrm{p}<0.001)$, AlexNX-56-08 (LC) $(\mathrm{p}<0.01 ; \mathrm{p}<0.001)$ and Alex2 (PST + LC) treatments ( $<<0.001 ; \mathrm{p}<0.001)$, than those of the corresponding controls (Fig. 4A and B). No significant differences between treatments were observed: Alex5 (PST), AlexNX-56-08 (LC) and Alex2 (PST + LC) within the same experimental period or between experimental periods (3 vs. 7 days).

\subsection{Immune function}

The number of circulating hemocytes was lower in mussels fed for 3 days with Alex5 (PST) and AlexNX-56-08 (LC) cells, than in control and Alex2 (PST + LC) treatments ( $p<0.01$ for all comparisons) (Fig. 5A).

Table 1

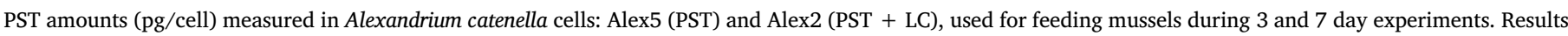
are expressed as mean \pm SEM.

\begin{tabular}{|c|c|c|c|c|c|c|c|}
\hline \multirow[t]{2}{*}{ Strain } & \multirow[t]{2}{*}{ Feeding } & \multicolumn{6}{|l|}{ Toxin (pg/cell) } \\
\hline & & STX & NEO & GTX1/4 & GTX2/3 & $\mathrm{C} 1 / \mathrm{C} 2$ & Total \\
\hline \multirow[t]{2}{*}{ Alex 5 (PST) } & 3 days & $3.84 \pm 0.05$ & $15.09 \pm 0.01$ & $24.61 \pm 0.01$ & $2.12 \pm 0.01$ & $33.90 \pm 0.02$ & 79.56 \\
\hline & 7 days & $2.63 \pm 0.31$ & $14.33 \pm 0.01$ & $23.82 \pm 0.28$ & $0.93 \pm 0.01$ & $30.72 \pm 0.08$ & 72.42 \\
\hline \multirow[t]{2}{*}{ Alex 2 (PST + LC) } & 3 days & $2.35 \pm 0.28$ & $6.10 \pm 0.01$ & $1.32 \pm 0.24$ & $0.18 \pm 0.01$ & $6.30 \pm 0.10$ & 16.25 \\
\hline & 7 days & $2.02 \pm 0.62$ & $6.97 \pm 0.02$ & $2.22 \pm 0.35$ & $0.22 \pm 0.01$ & $6.63 \pm 0.06$ & 18.25 \\
\hline
\end{tabular}


(A)

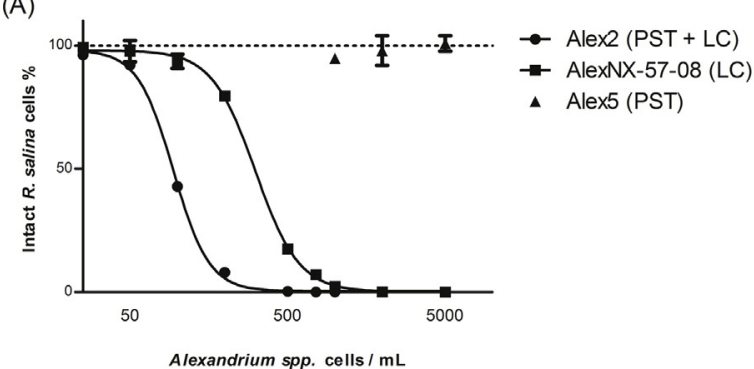

(B)

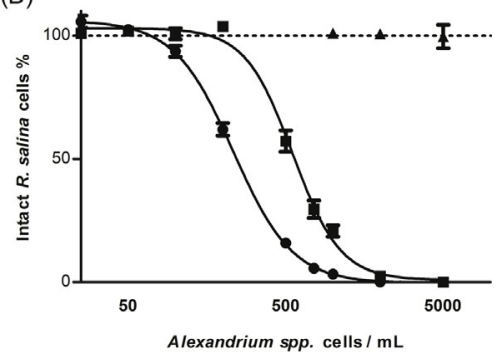

Fig. 1. Whole cell cryptophyte Rhodomonas salina bioassay showing lytic activity in whole cultures of Alexandrium spp.: Alex2 (PST + LC), Alex5 (PST), AlexNX-5608 (LC), used for feeding mussels during 3 (A) and 7 (B) day experiments, $n=3$.

Table 2

Percentage of cells of Nannochloropsis salina (Control) and Alexandrium spp.: Alex5 (PST), AlexNX-56-08 (LC), Alex2 (PST + LC), filtered by Mytilus edulis during 3 (A) and 7 day (B) experimental feeding. CI: condition index. Results are expressed as mean \pm SEM. ${ }^{*} p<0.05,{ }^{* *} p<0.01$ and $* * * p<0.01$ between Alex5 (PST) and the rest of the treatments, within the same day, $n=6$.

\begin{tabular}{lllll}
\hline (A) & Control & Alex5 (PST) & $\begin{array}{l}\text { AlexNX-56-08 } \\
(\mathrm{LC})\end{array}$ & Alex2 (PST + LC) \\
& & & \\
\hline Day 1 & $96.2 \pm 1.2$ & $97.0 \pm 0.9$ & $98.3 \pm 0.3$ & $97.3 \pm 0.6$ \\
Day 2 & $96.5 \pm 1.1$ & $95.3 \pm 2.0$ & $98.7 \pm 0.2$ & $97.4 \pm 0.2$ \\
Day 3 & $97.5 \pm 0.6$ & $95.1 \pm 2.0$ & $98.5 \pm 0.4$ & $97.3 \pm 1.2$ \\
CI & $11.7 \pm 0.4$ & $10.5 \pm 0.7$ & $11.6 \pm 1.2$ & $10.9 \pm 1.0$ \\
\hline (B) & Control & Alex5 (PST) & AlexNX-56-08 & Alex2 \\
& & & $(\mathrm{LC})$ & $(\mathrm{PST}+\mathrm{LC})$ \\
\hline Day 1 & $96.50 \pm 0.5$ & $93.17 \pm 4.2$ & $98.1 \pm 0.5$ & $96.6 \pm 1.5$ \\
Day 2 & $97.9 \pm 0.3$ & $95.88 \pm 1.3$ & $98.7 \pm 0.3$ & $93.9 \pm 1.6$ \\
Day 3 & $95.5 \pm 0.4$ & $96.23 \pm 1.2$ & $97.9 \pm 0.6$ & $94.6 \pm 2.2$ \\
Day 4 & $91.9 \pm 0.8$ & $93.84 \pm 4.4$ & $98.5 \pm 0.4$ & $97.6 \pm 1.1$ \\
Day 5 & $95.3 \pm 0.5$ & $72.5 \pm 9.3^{* * *}$ & $96.1 \pm 1.2$ & $98.3 \pm 0.7$ \\
Day 6 & $95.1 \pm 0.5$ & $86.1 \pm 7.8^{* *}$ & $97.0 \pm 1.3$ & $91.9 \pm 3.9$ \\
Day 7 & $94.2 \pm 0.6$ & $82.9 \pm 5.8^{* *}$ & $96.8 \pm 1.1$ & $87.8 \pm 7.3$ \\
CI & $10.8 \pm 0.7$ & $11.6 \pm 0.6$ & $11.4 \pm 0.9$ & $11.1 \pm 1.2$ \\
\hline
\end{tabular}

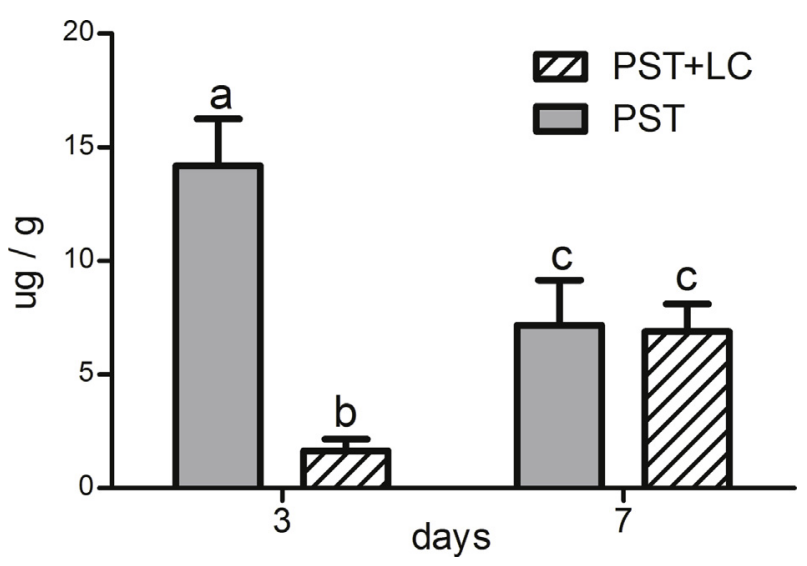

Fig. 2. Total PST accumulation in digestive gland of Mytilus edulis fed with Alexandrium catenella strains: Alex5 (PST) and Alex2 (PST + LC), during 3 and 7 days of experimentation. Different characters denote significant differences among treatments $(\mathrm{p}<0.05), \mathrm{n}=6$.

After 7 days, no significant differences were observed among treatments (Fig. 5B).

Phagocytic activity of hemocytes was higher in mussels fed for 3 days with Alex5 (PST) cells than in mussels from control $(p<0.01)$, AlexNX-56-08 (LC) $(p<0.01)$ and Alex2 (PST + LC) $(\mathrm{p}<0.05)$ treatments (Fig. 6A). After 7 days, no significant differences were observed among treatments (Fig. 6B).

\subsection{ROS production}

Intracellular ROS production was lower in mussels fed 3 days with Alex5 (PST), AlexNX-56-08 (LC) and Alex2 (PST + LC) cells, than in mussels from control ( $p<0.05$, for all comparisons), whereas no differences were observed among treatments after 7 days (Fig. 7A and B). Extracellular ROS levels were lower in mussel hemolymph after 3 days of the Alex2 (PST + LC) treatment than in controls $(p<0.05)$, and this effect was significantly higher in mussels fed with only Alex5 (PST) $(p<0.01)$ or only AlexNX-56-08 (LC) cells ( $p<0.01$,Fig. 7C). After 7 days, extracellular ROS were significantly lower in mussels of the Alex2 (PST + LC) treatment than in controls and Alex5 (PST) treatments ( $p<0.05$, for both comparisons) (Fig. 7D).

\section{Discussion}

All of the observed harmful effects that Alexandrium exerts on shellfish can be attributed to at least one out of two different compound classes produced separately or as a combination in different strains: PSP toxins (PST) and lytic compounds (LC). To better separate the effects of both compound classes, and to understand combined or synergistic effects on the mussels, we used three well-characterized strains of Alexandrium and investigated sublethal markers of functional disturbance, using whole animals and their hemocyte cells as indicators.

\subsection{Effects of individual compound classes}

The effect that was exclusively attributable to PST was the enhanced hemocyte phagocytic activity after three exposure days to the most toxic cells (Alex 5) and caused a reduction of feeding activity (cell absorption) upon prolonged exposure ( $>5$ days). This would explain why injection of $A$. catenella STX extract induced the expression of phagocytosis-related genes in M. chilensis hemocytes [23]. Reduced feeding rate is the main mechanism through which filtering organisms avoid harmful diets [30]. Particularly, M. chilensis displays small and temporal reductions of ingestion rates when PST-producer A. catenella is included in the diet $[8,9]$. In our work, the supply of a highly toxic mono-diet may have caused a reduction of filtering activity [1] in Alex5 (PST) treated mussels after five days of feeding. Recovery of $M$. edulis phagocytic activity after seven feeding days can hence be linked to decreased toxin uptake from reduced ingestion. As shown earlier for oysters fed with $A$. catenella [22], altered feeding activity leads to a decrease of PST content in digestive gland of $M$. edulis after seven days of feeding with Alex5 (PST). Contrarily to the effects observed in scallops [29] and oysters [48], the reduction in feeding activity is not shown to be related to LC exposure in $M$. edulis.

Paralysis was not clearly relatable to either compounds class. The negligible response of mussels to neurotoxic effects of PST exposure reflects their unusual tolerance to feed on PST producing microalgae [1]. The bacterial biofilm of the digestive tract of $M$. edulis was shown to reduce up to $90 \%$ of PST toxicity of Alexandrium spp. (a strain 
(A)

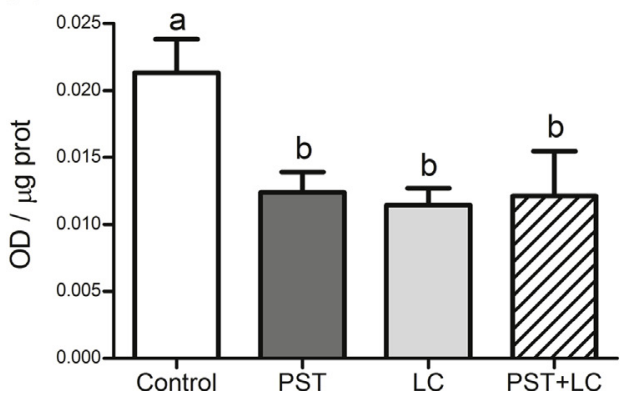

(A)

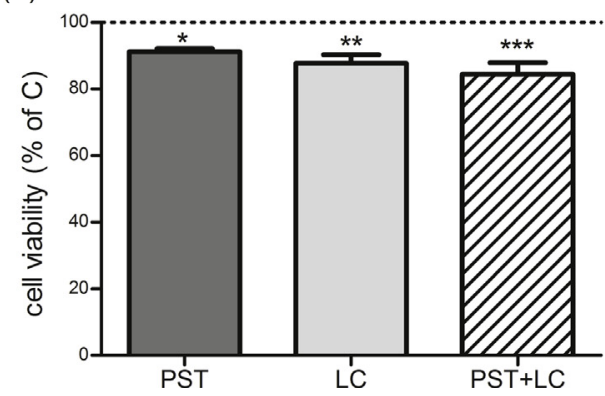

(B)

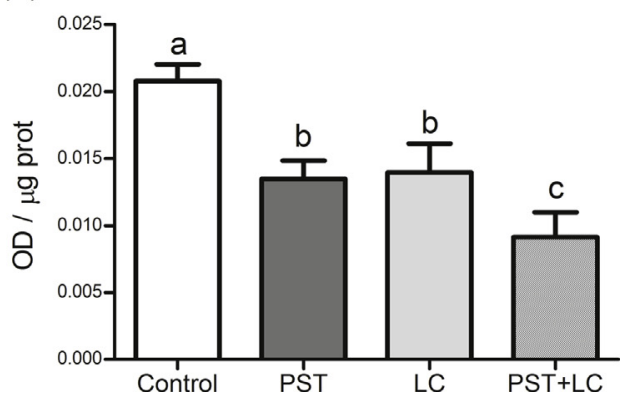

(B)

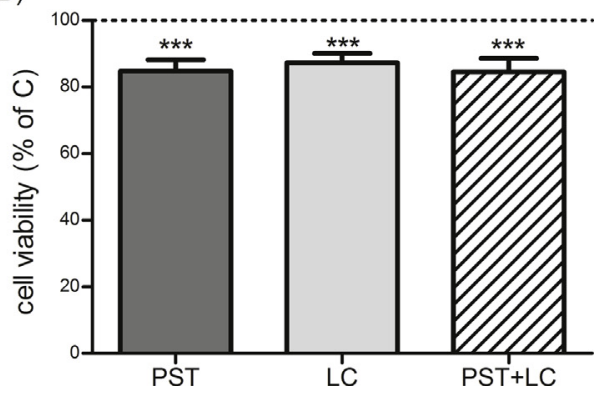

Fig. 3. Lysosomal membrane stability in hemocytes of Mytilus edulis fed with Nannochloropsis salina (control) and Alexandrium spp. strains: Alex5 (PST), AlexNX-56-08 (LC), Alex2 (PST + LC), during 3 (A) and 7 day (B) experiments. OD: optical density. Different characters denote significant differences among treatments $(p<0.05), \mathrm{n}=6$.
(A)

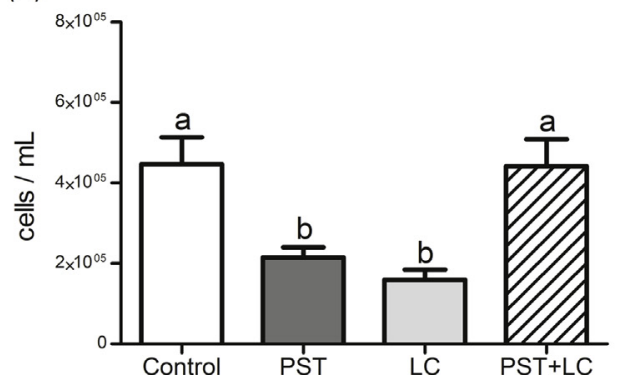

(B)
Fig. 4. Hemocyte viability in Mytilus edulis fed with Nannochloropsis salina (control 100\%) and Alexandrium spp. strains: Alex5 (PST), AlexNX-56-08 (LC) and Alex2 (PST + LC), during 3 (A) and 7 day (B) experiments. Asterisks denote significant differences between each treatment and the control treatments $\left({ }^{*} p<0.05\right.$; $* * p<0.01 ; * * * p<0.001), \mathrm{n}=6$.

Fig. 5. Total number of hemocytes in hemolymph of Mytilus edulis fed with Nannochloropsis salina (control) and Alexandrium spp. strains: Alex5 (PST), AlexNX-56-08 (LC) and Alex2 (PST + LC), during 3 (A) and 7 day (B) experiments. Different characters denote significant differences among treatments $(p<0.05), \mathrm{n}=6$.

(A)

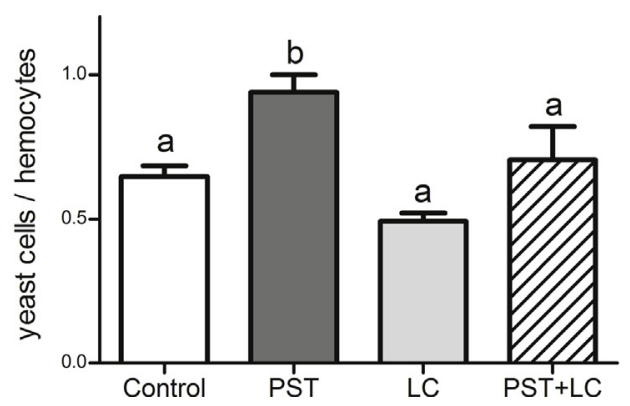

(B)

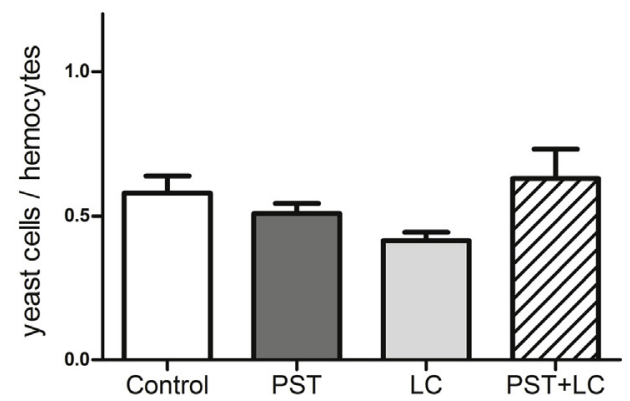

Fig. 6. Hemocyte phagocytic activity of Mytilus edulis fed with Nannochloropsis salina (control) and Alexandrium spp. strains: Alex5 (PST), AlexNX-56-08 (LC) and Alex2 (PST + LC), during 3 (A) and 7 day (B) experiments. Different characters denote significant differences among treatments $(p<0.05)$, $\mathrm{n}=6$.

reported as "A. tamarense" but of unknown molecular identity) [49]. In scallops, for instance enzymatic biotransformation and accumulation in labial palps and digestive glands may contribute to block the passage of PST to gill, mantle and adductor muscle [7]. Mortality events are not frequently reported in Mytilus spp. fed with PST-producer algae [8,9, among others]. Only one mussel out of 30 died after seven days of feeding with Alex5 (PST), which renders difficult to attribute mortality to PST in this case. Movement/feeding impairment and no mortality were observed in scallops [29] and oysters [48] exposed to the BC producer A. minutum. To our knowledge, such effects have not been previously evaluated in M. edulis exposed to Alexandrium BC producing strains.

Hemocytes of mussels exposed to the strain with high PST content showed neither diminished hemocyte viability, nor was lysosomal membrane destabilization exaggerated over the other treatment groups. An oxidative burst response (enhanced intracellular and/or extracellular ROS) was not clearly evident, although the Alex 5 (PST) exposed mussels had the highest ROS levels after seven days of exposure, 
(A)

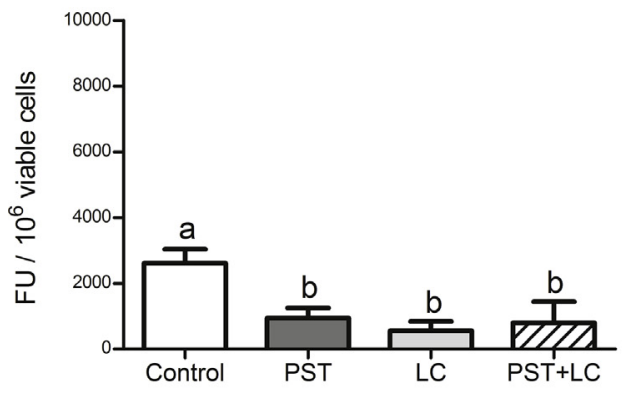

(C)

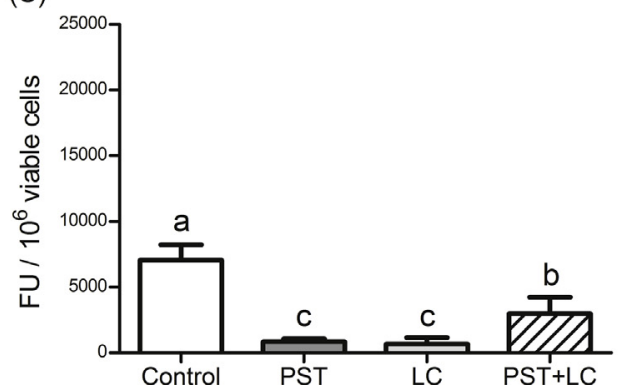

(B)

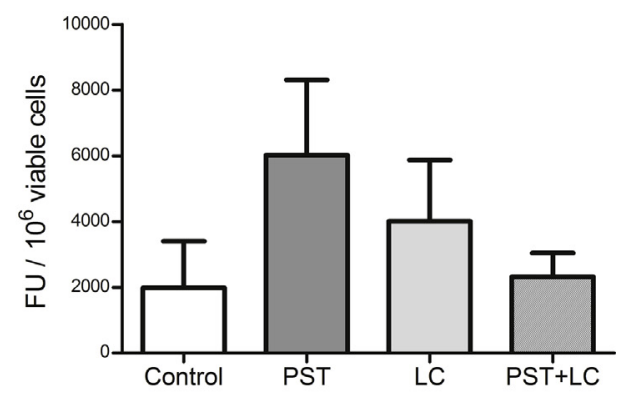

(D)

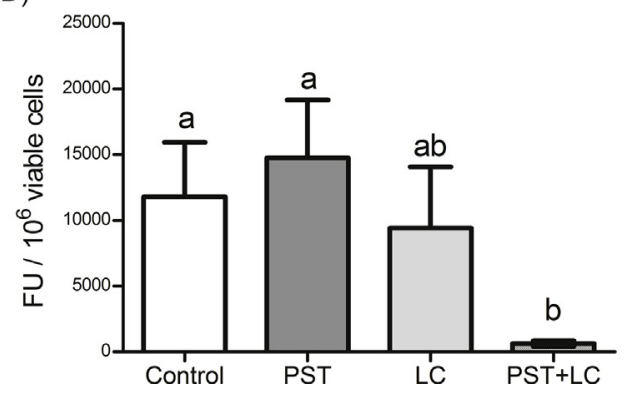

Fig. 7. Fluorescence units (FU) indicating intracellular ROS production (A,B) and extracellular ROS levels (C,D) in hemocytes of Mytilus edulis fed with Nannochloropsis salina (control) and Alexandrium spp. strains: Alex5 (PST), AlexNX-56-08 (LC) and Alex2 $(\mathrm{PST}+\mathrm{LC})$, during $3(\mathrm{~A}, \mathrm{C})$ and 7 day $(\mathrm{B}, \mathrm{D})$ experiments. Different characters denote significant differences among treatments $(p<0.05), \mathrm{n}=6$. but the effect did not reach statistical significance.

Cytotoxic effects of LCs produced by Alexandrium spp. are clearly based on their direct disruptive effect on membranes, increasing permeability and leading to cell death, as was previously shown for various species of photosynthetic and heterotrophic protists [24,32] and in rat neuroendocrine PC12 cells [50]. Interestingly, increased lysosomal destabilization in our experiments after seven days of feeding with Alex2 (PST + LC) cells is likely attributable to a time and dose dependent response to LC. Direct damage of circulating hemocyte membranes by LC would not be expected during in vivo exposures, since there is no evidence of lytic damage on internal organs of aquatic organisms exposed to Alexandrium spp. LC-producer strains [51]. Alternatively, physiological stress produced as a consequence of gill/intestine tissue damage, lipid oxidation in digestive gland, mantle and muscle, and possibly respiratory impairment $[29,52]$ may be causing indirect sublethal damage to hemocytes, with early manifestation in the form of lysosome destabilization [53]. However, enhanced lysosomal labialization in Alex2 (PST + LC) treated mussels was not accompanied by increased hemocyte mortality. This could indicate that the harmful effects are not strong enough to increase cell death, and/or that hemocytes display some kind of adaptive mechanism to this stressful conditions.

\subsection{Shared and combined effects of PST and LC on circulating hemocytes}

After three days, the total number of circulating hemocytes was affected by feeding on algal strains exclusively producing either PST or LC. This suggests cellular diapedesis and tissue accumulation as inflammatory response to toxic cell encapsulation or PST detoxification [54]. Specific mechanisms involving increased toxin-lipofuscin complex accumulation in lysosomes of hemocytes has been proposed as mechanism for PST elimination in the intestinal lumen of $M$. edulis after feeding on Alexandrium (a strain reported as "A. fundyense" but of unknown molecular identity) [55]. In this context, Borcier et al. [29] suggested that direct contact with bioactive compound producing $A$. minutum cells leads to hemocyte infiltration of affected tissues. It is therefore interesting to note that in our experiment both toxins when applied in the diet as a combination had the reverse effect and rather stabilized the number of circulating hemocytes at control level, counteracting the reducing effect of the single substance application. The same recovery response was observed after seven days for all mussels treated separately with PST or LC producer algae. As suggested by Galimany et al. [55] and Haberkorn et al. [4], these results could indicate increased hemocyte production and stocking in hemolymph under strong toxicity exposure (dose/time) to support tissue infiltration for defense against toxic algae.

Intracellular ROS production and consequently the extracellular ROS levels of $M$. edulis hemocytes were reduced following three days of exposure to all three Alexandrium strains. Undiminished phagocytic activity indicates that an "oxidative burst" is not always associated with phagocytosis in bivalves [18,54], and that ROS production might be curtailed by the chemical action of both types of toxins. Haberkorn et al. [4] speculated that reduced ROS production in hemocytes of oysters fed with $A$. minutum could be caused by high PST accumulation, which exceeded the "tolerance" of these bivalves, affecting their physiological and metabolic activities directly and profoundly. However, the A. minutum strain (AM89BM) used by Haberkorn et al. [4] was later on described to produce also extracellular BC [28]. Mello et al. [21] suggested that both PST and allelopathic/lytic compounds produced by this algae reduce ROS production in oyster hemocytes. Inhibition of ROS production in hemocytes of clams exposed to hemolytic supernatant of Karenia selliformis was also related to physiological impairment by cellular damage [54]. The fact that both intracellular ROS production and extracellular ROS levels were back to control values after seven days of feeding indicates physiological recovery and reactivation of the normal immune response, in spite of continued exposure to separate toxins. Wooton et al. [56] suggested that high basal levels of phagocytosis, cellular enzyme activity and superoxide generation in $M$. edulis hemocytes might explain its considerable resilience to adverse environmental conditions, compared to other bivalve species. However, strong suppression of extracellular ROS levels were observed after seven days of feeding with Alex2 (PST + LC), which would indeed represent immune impairment upon exposure to the toxin combination.

\section{Conclusion}

Both compound classes caused paralysis and affected hemocyte integrity and function. However, we showed that increased phagocytosis and impairment of feeding activity are clearly associated to PST-specific 
effects, when mussels are exposed in vivo to harmful algae; while lysosomal membrane labilization seems to be a LC effect, albeit not exclusively. In addition, our results support earlier findings describing the astonishing resilience of $M$. edulis to prolonged exposure to PST and/or LC producing Alexandrium spp. Bivalves displayed adaptive fitness traits in maintaining stable hemocyte viability, restoring phagocytic activity, and limiting intracellular ROS production upon feeding under environmentally relevant HAB conditions (cell concentrations and exposure duration). Knowledge gaps remain with respect to dose-dependent PST and LC effects on hemocyte cells.

\section{Acknowledgments}

This work was supported by a short-term grant from German Academic Exchange Service to VB ( $\mathrm{N}^{\circ}$ 91612818). Authors would like to acknowledge Stefanie Meyer for technical support.

\section{References}

[1] V.M. Bricelj, S.E. Shumway, Reviews in fisheries science paralytic shellfish toxins in bivalve Molluscs : occurrence, transfer kinetics, and biotransformation paralytic shellfish toxins in bivalve Molluscs : occurrence, transfer kinetics, and biotransformation, Rev. Fish. Sci. 6 (1998) 315-383, https://doi.org/10.1080/ 10641269891314294.

[2] M. Wiese, P.M. D'Agostino, T.K. Mihali, M.C. Moffitt, B.A. Neilan, Neurotoxic alkaloids: saxitoxin and its analogs, Mar. Drugs 8 (2010) 2185-2211, https://doi.org/ $10.3390 / \mathrm{md} 8072185$.

[3] S.E. Ford, V.M. Bricelj, C. Lambert, C. Paillard, Deleterious effects of a nonPST bioactive compound(s) from Alexandrium tamarense on bivalve hemocytes, Mar. Biol. 154 (2008) 241-253, https://doi.org/10.1007/s00227-008-0917-z.

[4] H. Haberkorn, C. Lambert, N. Le Goic, M. Guéguen, J. Moal, E. Palacios, P. Lassus, P. Soudant, Effects of Alexandrium minutum exposure upon physiological and hematological variables of diploid and triploid oysters, Crassostrea giga, Aquat. Toxicol. 97 (2010) 96-108, https://doi.org/10.1016/j.aquatox.2009.12.006.

[5] H. Hégaret, K.B. Brokordt, C.F. Gaymer, K.B. Lohrmann, C. García, D. Varela, Effects of the toxic dinoflagellate Alexandrium catenella on histopathogical and escape responses of the Northern scallop Argopecten purpuratus, Harmful Algae 18 (2012) 74-83, https://doi.org/10.1016/j.hal.2012.04.006.

[6] S.M. Etheridge, Paralytic shellfish poisoning: seafood safety and human health perspectives, Toxicon 56 (2010) 108-122, https://doi.org/10.1016/j.toxicon.2009. 12.013

[7] N.A. Estrada, N. Lagos, C. García, A.N. Maeda-Martínez, F. Ascencio, Effects of the toxic dinoflagellate Gymnodinium catenatum on uptake and fate of paralytic shellfish poisons in the Pacific giant lions-paw scallop Nodipecten subnodosus, Mar. Biol. 151 (2007) 1205-1214, https://doi.org/10.1007/s00227-006-0568-x.

[8] M.J. Fernández-Reiriz, J.M. Navarro, A.M. Contreras, U. Labarta, Trophic interactions between the toxic dinoflagellate Alexandrium catenella and Mytilus chilensis: feeding and digestive behaviour to long-term exposure, Aquat. Toxicol. 87 (2008) 245-251, https://doi.org/10.1016/j.aquatox.2008.02.011.

[9] J.M. Navarro, A.M. Contreras, An integrative response by Mytilus chilensis to the toxic dinoflagellate Alexandrium catenella, Mar. Biol. (2010) 1967-1974, https:// doi.org/10.1007/s00227-010-1465-x.

[10] W. Medhioub, P. Lassus, P. Truquet, M. Bardouil, Z. Amzil, V. Sechet, M. Sibat, P. Soudant, Spirolide uptake and detoxification by Crassostrea gigas exposed to the toxic dinoflagellate Alexandrium ostenfeldii, Aquaculture 358-359 (2012) 108-115, https://doi.org/10.1016/j.aquaculture.2012.06.023.

[11] B. Krock, C.G. Seguel, A.D. Cembella, Toxin profile of Alexandrium catenella from the Chilean coast as determined by liquid chromatography with fluorescence detection and liquid chromatography coupled with tandem mass spectrometry, Harmful Algae 6 (5) (2007) 734-744, https://doi.org/10.1016/j.hal.2007.02.005.

[12] V.M. Bricelj, L. Connell, K. Konoki, S.P. MacQuarrie, T. Scheuer, W.A. Catterall, V.L. Trainer, Sodium channel mutation leading to saxitoxin resistance in clams increases risk of PSP, Nature 434 (2005) 763-767, https://doi.org/10.1038/ nature03415.

[13] H. Hégaret, G.H. Wikfors, P. Soudant, C. Lambert, S.E. Shumway, J.B. Bérard, P. Lassus, Toxic dinoflagellates (Alexandrium fundyense and $A$. catenella) have minimal apparent effects on oyster hemocytes, Mar. Biol. 152 (2007) 441-447, https://doi.org/10.1007/s00227-007-0703-3.

[14] V.M. Bricelj, S.E. Ford, C. Lambert, A. Barbou, C. Paillard, Effects of toxic Alexandrium tamarense on behavior, hemocyte responses and development of brown ring disease in Manila clams, Mar. Ecol. Prog. Ser. 430 (2011) 35-48, https://doi. org/10.3354/meps09111.

[15] L. Basti, S. Nagai, J. Go, S. Okano, K. Nagai, R. Watanabe, T. Suzuki, Y. Tanaka, Differential inimical effects of Alexandrium spp. and Karenia spp. on cleavage, hatching, and two larval stages of Japanese pearl oyster Pinctada fucata martensii, Harmful Algae 43 (2015) 1-12, https://doi.org/10.1016/j.hal.2014.12.004.

[16] H. Haberkorn, C. Lambert, N.L. Goïc, J. Moal, M. Suquet, M. Guéguen, I. Sunila, P. Soudant, Effects of Alexandrium minutum exposure on nutrition-related processes and reproductive output in oysters Crassostrea gigas, Harmful Algae 9 (2010) 427-439, https://doi.org/10.1016/j.hal.2010.01.003.
[17] T. Yan, M. Zhou, M. Fu, Y. Wang, R. Yu, J. Li, Inhibition of egg hatching success and larvae survival of the scallop, Chlamys farreri, associated to exposure of cells and cell fragments of the dinoflagellate Alexandrium tamarense, Toxicon 39 (2001) 1239-1244.

[18] L. Donaghy, C. Lambert, K.-S. Choi, P. Soudant, Hemocytes of the carpet shell clam (Ruditapes decussatus) and the Manila clam (Ruditapes philippinarum): current knowledge and future prospects, Aquaculture 297 (2009) 10-24, https://doi.org/ 10.1016/j.aquaculture.2009.09.003.

[19] E.E. Philipp, S. Lipinski, J. Rast, P. Rosenstiel, Immune defense of marine invertebrates: the role of reactive oxygen and nitrogen species, Oxidative stress in aquatic ecosystems (2012) 236-246, https://doi.org/10.1002/9781444345988. ch17.

[20] H. Hégaret, P.M. da Silva, G.H. Wikfors, C. Lambert, T. De Bettignies, S.E. Shumway, P. Soudant, Hemocyte responses of Manila clams, Ruditapes philippinarum, with varying parasite, Perkinsus olseni, severity to toxic-algal exposures, Aquat. Toxicol. 84 (2007) 469-479, https://doi.org/10.1016/j.aquatox.2007.07. 007.

[21] D.F. Mello, P.M. da Silva, M.A. Barracco, P. Soudant, H. Hégaret, Effects of the dinoflagellate Alexandrium minutum and its toxin (saxitoxin) on the functional activity and gene expression of Crassostrea gigas hemocytes, Harmful Algae 26 (2013) 45-51, https://doi.org/10.1016/j.hal.2013.03.003.

[22] M. Lassudrie, P. Soudant, J.L. Nicolas, P. Miner, J. Le Grand, C. Lambert, N. Le Goïc, H. Hégaret, C. Fabioux, Exposure to the toxic dinoflagellate Alexandrium catenella modulates juvenile oyster Crassostrea gigas hemocyte variables subjected to different biotic conditions, Fish Shellfish Immunol. 51 (2016) 104-115, https://doi. org/10.1016/j.fsi.2016.02.017.

[23] G. Núñez-Acuña, A.E. Aballay, H. Hégaret, A.P. Astuya, C. Gallardo-Escárate, Transcriptional responses of Mytilus chilensis exposed in vivo to saxitoxin (STX), J. Molluscan Stud. 79 (2013) 323-331, https://doi.org/10.1093/mollus/eyt030.

[24] U. Tillmann, U. John, Toxic effects of Alexandrium spp. on heterotrophic dinoflagellates: an allelochemical defence mechanism independent of PSP-toxin content, Mar. Ecol. Prog. Ser. 230 (2002) 47-58, https://doi.org/10.3354/meps230047.

[25] H. Ma, B. Krock, U. Tillmann, A. Muck, N. Wielsch, A. Svatoš, A. Cembella, Isolation of activity and partial characterization of large non-proteinaceous lytic allelochemicals produced by the marine dinoflagellate Alexandrium tamarense, Harmful Algae 11 (2011) 65-72, https://doi.org/10.1016/j.hal.2011.07.004.

[26] Y. Matsuyama, H. Usuki, T. Uchida, Y. Kotani, Effects of harmful algae on the early planktonic larvae of the oyster, Crassostrea gigas, in: G.M. Hallegraeff, S.I. Blackburn, C.J. Olch, R.J. Lewis (Eds.), Harmful Algal Blooms, Proceedings of the Ninth International Conference on Harmful Algal Blooms 2000, UNESCO, France, 2001, pp. 411-414.

[27] G. Arzul, M. Seguel, L. Guzman, E. Erard-Le Denn, Comparison of allelopathic properties in three toxic Alexandrium species, J. Exp. Mar. Biol. Ecol. 232 (1999) 285-295, https://doi.org/10.1016/S0022-0981(98)00120-8.

[28] A. Lelong, H. Haberkorn, N. Le Goc, H. Hégaret, P. Soudant, A new insight into allelopathic effects of Alexandrium minutum on photosynthesis and respiration of the diatom chaetoceros neogracile revealed by photosynthetic-performance analysis and flow cytometry, Microb. Ecol. 62 (2011) 919-930, https://doi.org/10.1007/ s00248-011-9889-5.

[29] E. Borcier, R. Morvezen, P. Boudry, P. Miner, G. Charrier, J. Laroche, H. Hegaret, Effects of bioactive extracellular compounds and paralytic shellfish toxins produced by Alexandrium minutum on growth and behaviour of juvenile great scallops Pecten maximus, Aquat. Toxicol. 184 (2017) 142-154, https://doi.org/10.1016/j.aquatox. 2017.01.009.

[30] J.H. Landsberg, The effects of harmful algal blooms on aquatic organisms, Rev. Fish Sci. (2002) 113-390, https://doi.org/10.1080/20026491051695.

[31] U. John, R.W. Litaker, M. Montresor, S. Murray, M.L. Brosnahan, D.M. Anderson, Formal revision of the Alexandrium tamarense species complex (Dinophyceae) taxonmomy: the introduction of five species with emphasis on molecular-based (rDNA) classification, Protist 165 (2014) 779-804.

[32] U. Tillmann, T.L. Alpermann, R.C. da Purificação, B. Krock, A. Cembella, Intrapopulation clonal variability in allelochemical potency of the toxigenic dinoflagellate Alexandrium tamarense, Harmful Algae 8 (2009) 759-769, https://doi. org/10.1016/j.hal.2009.03.005.

[33] I. Okomus, N. Bascinar, M. Ozkan, The effects of phytoplankton concentration, size of mussel and water temperature on feed consumption and filtration rate of the Mediterranean mussel (Mytilus galloprovincialis Lmk), Turk. J. Zool. 26 (2002) $167-172$.

[34] M. Diener, K. Erler, S. Hiller, B. Christian, B. Luckas, Determination of paralytic shellfish poisoning (PSP) toxins in dietary supplements by application of a new HPLC/FD method, Eur. Food Res. Technol. 224 (2) (2006) 147-151.

[35] H. Ma, B. Krock, U. Tillmann, A. Cembella, Preliminary characterization of extracellular allelochemicals of the toxic marine dinoflagellate Alexandrium tamarense using a Rhodomonas salina bioassay, Mar. Drugs 7 (2009) 497-522, https://doi.org/ $10.3390 / \mathrm{md} 7040497$.

[36] V.A. Bianchi, J.M. Castro, I. Rocchetta, F. Bieczynski, C.M. Luquet, Health status and bioremediation capacity of wild freshwater mussels (Diplodon chilensis) exposed to sewage water pollution in a glacial Patagonian lake, Fish Shellfish Immunol. 37 (2014) 268-277, https://doi.org/10.1016/j.fsi.2014.02.013.

[37] M. Starr, J.H. Himmelman, J.-C. Therriault, Direct coupling of marine invertebrate spawning with phytoplankton blooms, Science 247 (4946) (1990) 1071-1074, https://doi.org/10.1126/science.247.4946.1071.

[38] C. Kittner, H.U. Riisgård, Marine Effect of temperature on filtration rate in the mussel Mytilus edulis: no evidence for temperature compensation, Mar. Ecol. Prog. Ser. 305 (2005) 147-152, https://doi.org/10.3354/Meps305147.

[39] J. Widdows, The effects of temperature on the metabolism and activity of Mytilus 
edulis, Neth. J. Sea Res. 7 (1973) 387-398, https://doi.org/10.1016/0077-7579(73) 90060-4.

[40] H.G. Gudfinnsson, A. Eydal, K. Gunnarsson, K. Gudmundsson, K. Valsdóttir, Monitoring of toxic phytoplankton in three Icelandic fjords, ICES CM 12 (2010) $1-18$.

[41] B. Luckas, K. Erler, B. Krock, Analysis of marine biotoxins using LC-MS/MS, chapter 18: 277-297, in: D. Stengel, S. Connan (Eds.), Natural Products from Marine Algae, Humana Press, Springer, New York, Heidelberg, Dordrecht, London, 2015ISBN: 978-1-4939-2683-1.

[42] A. Novas, R. Barcia, J.I. Ramos-Martínez, After the Prestige oil spill modifications in NO production and other parameters related to the immune response were detected in hemocytes of Mytilus galloprovincialis, Aquat. Toxicol. 85 (2007) 285-290, https://doi.org/10.1016/j.aquatox.2007.09.011.

[43] J. Coles, S. Farley, R. Pipe, Alteration of the immune response of the common marine mussel Mytilus edulis resulting from exposure to cadmium, Dis. Aquat. Org. 22 (1995) 59-65, https://doi.org/10.3354/dao022059.

[44] M. Bradford, Bradford Protein Assay Protocol, (2006), pp. 1-3, https://doi.org/10. 1016/0165-022X(93)90047-R October.

[45] F.M. Akaishi, S.D. St-Jean, F. Bishay, J. Clarke, I. da S. Rabitto, C.A. de O. Ribeiro, Immunological responses, histopathological finding and disease resistance of blue mussel (Mytilus edulis) exposed to treated and untreated municipal wastewater, Aquat. Toxicol. (2007), https://doi.org/10.1016/j.aquatox.2007.01.008.

[46] R.P. Kuchel, D.A. Raftos, S. Nair, Immunosuppressive effects of environmental stressors on immunological function in Pinctada imbricata, Fish Shellfish Immunol. 29 (6) (2010) 930-936, https://doi.org/10.1016/j.fsi.2010.07.033.

[47] B. Moss, B. Allam, Fluorometric measurement of oxidative burst in lobster hemocytes and inhibiting effect of pathogenic bacteria and hypoxia, J. Shellfish Res. 25 (2006) 1051-1057.

[48] J. Castrec, P. Soudant, L. Payton, D. Tran, P. Miner, C. Lambert, N.L. Goïc, A. Huvet, V. Quillien, F. Boullot, Z. Amzil, H. Hégaret, C. Fabioux, Bioactive extracellular compounds produced by the dinoflagellate Alexandrium minutum are highly detrimental for oysters, Aquat. Toxicol. 199 (2018) 188-198, https://doi.org/10. 1016/j.aquatox.2018.03.034.

[49] C.J. Donovan, J.C. Ku, M.A. Quilliam, T.A. Gill, Bacterial degradation of paralytic shellfish toxins, Toxicon 52 (2008) 91-100, https://doi.org/10.1016/j.toxicon. 2008.05.005.

[50] H. Ma, B. Krock, U. Tillmann, U. Bickmeyer, M. Graeve, A. Cembella, Mode of action of membrane-disruptive lytic compounds from the marine dinoflagellate Alexandrium tamarense, Toxicon 58 (2011) 247-258, https://doi.org/10.1016/j. toxicon.2011.06.004.

[51] J.H. Landsberg, The effects of harmful algal blooms on aquatic organisms, Rev. Fish Sci. 10 (2) (2002) 113-390, https://doi.org/10.1080/20026491051695.

[52] L. Basti, T. Oda, K. Nagai, S. Nagai, Role of cytotoxicity and hemolysis in the deleterious effects of Alexandrium affine and A. catenella on early-life development of the Japanese pearl oyster, Pinctada fucata martensii, J. Shellfish Res. 34 (2015) 608.

[53] A. Viarengo, D. Lowe, C. Bolognesi, E. Fabbri, A. Koehler, The use of biomarkers in biomonitoring: a 2-tier approach assessing the level of pollutant-induced stress syndrome in sentinel organisms, Comp. Biochem. Physiol. C Toxicol. Pharmacol. 146 (2007) 281-300, https://doi.org/10.1016/j.cbpc.2007.04.011.

[54] H. Hégaret, P.M. Da Silva, G.H. Wikfors, H. Haberkorn, S.E. Shumway, P. Soudant, In vitro interactions between several species of harmful algae and haemocytes of bivalve mollusks, Cell Biol. Toxicol. 27 (2011) 249-266, https://doi.org/10.1007/ s10565-011-9186-6.

[55] E. Galimany, I. Sunila, H. Hégaret, M. Ramón, G.H. Wikfors, Experimental exposure of the blue mussel (Mytilus edulis, L.) to the toxic dinoflagellate Alexandrium fundyense: histopathology, immune responses, and recovery, Harmful Algae 7 (2008) 702-711, https://doi.org/10.1016/j.hal.2008.02.006.

[56] E.C. Wootton, E.A. Dyrynda, N.A. Ratcliffe, Bivalve immunity: comparisons between the marine mussel (Mytilus edulis), the edible cockle (Cerastoderma edule) and the razor-shell (Ensis siliqua), Fish Shellfish Immunol. 15 (2003) 195-210, https:// doi.org/10.1016/S1050-4648(02)00161-4. 